\title{
Sedative and anxiolytic effects of the methanolic extract of Leea indica (Burm. f.) Merr. leaf
}

\author{
Md. Obayed Raihan, ${ }^{1, *}$, Md. Razibul Habib ${ }^{2}$, Afrina Brishti ${ }^{3}$, Md. Mominur Rahman ${ }^{1}$, \\ Md. Moshfiqus Saleheen ${ }^{1}$, Mashudul Manna ${ }^{1}$
}

${ }^{1}$ Department of Pharmacy, International Islamic University Chittagong, Chittagong, Bangladesh;

${ }^{2}$ Department of Pharmacy, East West University, Dhaka, Bangladesh;

${ }^{3}$ Department of Pharmacy, Rajshahi University, Rajshahi, Bangladesh.

\begin{abstract}
The sedative and anxiolytic potential of Leea indica (Burm. f.) Merr., a Bangladeshi tribal medicinal plant was studied for the first time. The crude methanol extract of $L$. indica leaves was evaluated for its central nervous system (CNS) depressant effect using rodent behavioral models, such as hole cross, open field and thiopental sodium induced sleeping time tests for its sedative properties and an elevated plus-maze (EPM) test for its anxiolytic potential, respectively. The methanol extract of $L$. indica at doses of $200 \mathrm{mg} / \mathrm{kg}$, p.o. and 400 $\mathrm{mg} / \mathrm{kg}$, p.o., displayed a dose dependent suppression of motor activity, exploratory behavior (in hole cross and open field tests) and prolongation of thiopental induced sleeping time in mice; the highest CNS depressant effect was shown at a dose of $400 \mathrm{mg} / \mathrm{kg}$, p.o. In the EPM test, both doses of methanol extract significantly $(p<0.01)$ increased exploration to and time spent by the treated mice in EPM open arms in a dose dependent manner. These results provide in vivo evidence that leaves of $L$. indica in general have significant sedative and anxiolytic effects. However, these results may rationalize the scientific basis for use of this plant in traditional medicine for treatment of anxiety and related disorders.
\end{abstract}

Keywords: Neuropharmacology, open field, elevated plus-maze (EPM), medicinal plant, L. indica

\section{Introduction}

Anxiety disorders are the most common emotional disorders affecting people in all countries worldwide. It is reported that more than $20 \%$ of the adult population

\section{*Address correspondence to:}

Dr. Md. Obayed Raihan, Department of Pharmacy, International Islamic University Chittagong (IIUC), Chittagong-4203, Bangladesh.

e-mail: ronipharm2000@yahoo.com suffer from these conditions at some stage during their life $(1,2)$. Anxiety is a natural emotion but becomes a problem when it occurs too often. According to the U.S. National Institute of Mental Health (NIMH), anxiety disorders can be related to other mental/emotional disorders, including depression and traumatic events. They can also be related to other physical illnesses. These illnesses include endocrine disorders such as thyroid disorders and problems with glucose regulation in the body, including diabetes and hypoglycemia. Although medications can not fully cure anxiety disorders they can, to a great degree, relieve the symptoms and reduce their occurrences. Prescription drugs which are commonly used in treating anxiety disorders may include Benzodiazepines (commonly known as anxiolytics) and several types of antidepressants, especially those from the group of selective serotonin reuptake inhibitors (SSRI). $\beta$-Adrenergic blocking drugs, to be more precise, could also be prescribed for reducing the peripheral symptoms such as palpitations and tremors.

Leea indica (Burm. f.) Merr. (Family Leeaceae) is a large evergreen shrub or small tree (3-5) indigenous to tropical Asia, Australasia, and the Pacific and grown mostly in Bangladesh, India, China, Bhutan, and Malaysia. Plant pacifies vitiated pitta, diarrhea, dysentery, colic, ulcers, skin diseases, vertigo, and headache. Marma of Chittagong Hill Tracts, Bangladesh, prescribes combined root paste of this plant along with the root of Oreocnide integrifolia and Cissus repens for bubo and boils (6,7). The plant leaf is also used as a folk medicine in the treatment of insomnia, although it is not reported yet in the literature.

The present study dealt with various psychopharmacological effects of the methanol extract from the leaves of $L$. indica on some neuropharmacological experimental models. Previous biological studies have shown that it possessed strong antioxidant and antimicrobial activities but still there is no report showing the sedative and anxiolytic effect of $L$. indica leaves on an animal behavioral model. In view of that, it was thus necessary to expand the present study for sedative anxiolytic potential and possible mechanisms underlying action. 


\section{Materials and Methods}

\subsection{Drugs and chemicals}

The following drugs and chemicals were used in this study: diazepam (Square Pharmaceutical Ltd., Bangladesh), thiopental sodium (Gonoshastho Pharmaceuticals Ltd., Bangladesh), methanol (Sigma Chemicals Co., USA).

\subsection{Plant material}

The plant was collected from Forests of Chittagong Hill Tracts in October 2010 when leaves were in their maximum densities. The plant leaves were thoroughly washed with water and were dried in a hot air oven at room temperature for 7 days and at $40^{\circ} \mathrm{C}$ for the next 2 days.

\subsection{Preparation of plant extract}

The dried leaves were coarsely powdered and about $1,000 \mathrm{~g}$ of powdered material was macerated with 99\% methanol at room temperature for a period of 7 days with occasional shaking and stirring. The whole mixture was filtered and the filtrate thus obtained was concentrated using a rotary evaporator (Bibby RE200, Sterlin Ltd., UK) to get a viscous mass. The viscous mass was kept at room temperature under a ceiling fan to get a dried extract (about 10\%). The extract prepared was used for pharmacological screening.

\subsection{Animals}

White female albino mice (Swiss-webstar strain, 25-35 g body weight) were collected from the animal research branch of the International Center for Diarrheal Disease and Research, Bangladesh (ICDDRB). The animals were provided with standard laboratory food and tap water ad libitum and maintained on a natural day night cycle. All experiments were conducted under isolated and noiseless conditions. Test animals were divided into two groups at doses of 200 and $400 \mathrm{mg} / \mathrm{kg}$ body weight. The animals were acclimatized to laboratory conditions for one week prior to experimentation.

\subsection{Hole cross test}

The method was carried out as described by Takagi et al. (8). A steel partition was fixed in the middle of a cage of $30 \times 20$ $\times 14 \mathrm{~cm}$. A hole of $3 \mathrm{~cm}$ diameter was made at a height of $7.5 \mathrm{~cm}$ in the center of the cage. The animals were divided into control, positive control, and test groups containing five mice each. The test groups received methanol extract of $L$. indica at doses of 200 and $400 \mathrm{mg} / \mathrm{kg}$ body weight orally whereas the control group received vehicle $(1 \%$ Tween 80 in water). The number of passages of a mouse through the hole from one chamber to the other was counted for a period of $3 \mathrm{~min}$ at $0,30,60,90$, and $120 \mathrm{~min}$ after oral administration of both doses of the test drug.

\subsection{Open field test}

In the open field test, the animals were divided into control, positive control, and test groups containing five mice each. The test groups received methanol extract of the leaves of $L$. indica at doses of 200 and $400 \mathrm{mg} / \mathrm{kg}$ body weight orally whereas the control group received vehicle (1\% Tween 80 in water). The floor of a half square meter open field $(9,10)$ was divided into a series of squares each alternatively colored black and white. The apparatus had a $40 \mathrm{~cm}$ height wall. The number of squares visited by the animals was counted for 3 min at 0 , $30,60,90$, and $120 \mathrm{~min}$ after oral administration of both doses of the test drug.

\subsection{Thiopental sodium induced sleeping time test}

The animals were randomly divided into five groups consisting of five mice each. The test groups received methanol extract from the leaves of $L$. indica at doses of 200 and $400 \mathrm{mg} / \mathrm{kg}$ body weight while the positive control was treated with diazepam $(1 \mathrm{mg} / \mathrm{kg})$ and control vehicle ( $1 \%$ Tween 80 in water). Thirty minutes later, thiopental sodium $(40 \mathrm{mg} / \mathrm{kg})$ was administered to each mouse to induce sleep. The animals were observed for the latent period (time between thiopental administrations to loss of righting reflex) and duration of sleep i.e. time between the loss and recovery of righting reflex (11).

\subsection{EPM test}

The method initially suggested by Handley and Mithani was employed with minor modifications (12). The apparatus consists of two open arms $(5 \times 10 \mathrm{~cm})$ and two closed arms $(5 \times 10 \times 15 \mathrm{~cm})$ radiating from a platform $(5 \times 5 \mathrm{~cm})$ to form a plus-sign figure. The apparatus was situated $40 \mathrm{~cm}$ above the floor. The open arms edges were $0.5 \mathrm{~cm}$ in height to keep the mice from falling and the closed-arms edges were $15 \mathrm{~cm}$ in height. Sixty minutes after administration of the test drugs, each animal was individually placed in the center of the EPM and were allowed $5 \mathrm{~min}$ for free exploration. Next, the number of open and enclosed arm entries, and time spent on open arms were manually registered (13). Entry into an arm was defined as the point when the animal placed all four paws onto the arm. The percentage of open arm entries $(100 \times$ open/total entries $)$ and the percentage of time spent in the open arms $(100 \times$ open/(open + enclosed)) were calculated for each animal. Observations made from an adjacent corner produced significant ( $p$ $<0.001, p<0.05$ ) decreases of locomotion from its initial value during the period of the experiment (Table 1). Maximum suppression of locomotor activity was displayed at the dose of $400 \mathrm{mg} / \mathrm{kg}$ body weight, which 
was comparable to the reference drug diazepam.

\subsection{Statistical analysis}

Data were expressed as mean \pm standard error of mean (S.E.M.). Statistical comparisons were performed using one way ANOVA followed by Dunnett's multiple comparison test (DMCT). The values obtained were compared with the vehicle control group and were considered statistically significant when $p<0.05$.

\section{Results}

\subsection{Thiopental sodium induced sleeping time test}

In the thiopental induced hypnosis test, methanol extract of leaves of L. indica at the dose of $400 \mathrm{mg} / \mathrm{kg}$, induced the sleep at an earlier stage while the same extract at the dose of $200 \mathrm{mg} / \mathrm{kg}$ was also found to have a dose dependent effect on the onset of thiopental induced sleep. In addition, both doses dependently prolonged the duration of sleeping time in test animals compared to controls (Figure 1).

\section{Table 1. EPM test of $L$. indica}

\begin{tabular}{lcc}
\hline Animal group & $\begin{array}{c}\text { \% number of entry } \\
\text { into open arm }\end{array}$ & $\begin{array}{c}\% \text { time (in seconds) spent } \\
\text { in open arm }\end{array}$ \\
\hline I (Control) & $55.88 \pm 2.133$ & $51.93 \pm 8.243$ \\
II (Diazepam) & $76.28 \pm 1.847^{* *}$ & $79.39 \pm 5.749^{*}$ \\
III (L. indica 400) & $80.27 \pm 2.524^{* *}$ & $86.13 \pm 5.355^{*}$ \\
IV (L. indica 200) & $65.71 \pm 2.607^{*}$ & $68.33 \pm 4.201$ \\
\hline
\end{tabular}

Effect of methanolic extract from $L$. indica on the percentage number of entries and the time in seconds spent in open arms of the EPM during the 5-min test session. Values are mean \pm S.E.M., $(n=5) ;{ }^{*} p$ $<0.05,{ }^{* *} p<0.01$, Dunnet test as compared to control (Vehicle $=0.4$ $\mathrm{mL} /$ mouse).
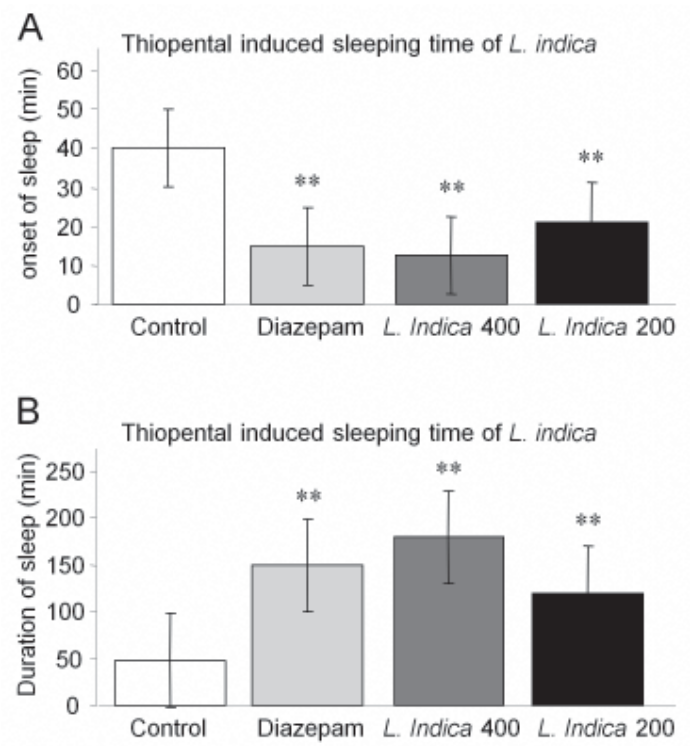

Figure 1. Effect of methanol extract from leaves of $L$. indica on thiopental induced sleeping time in mice. Values are mean \pm S.E.M., $(n=5){ }^{*} p<0.05,{ }^{* *} p<0.01$. Dunnet test as compared to control (Vehicle $=0.4 \mathrm{~mL} /$ mouse).

\subsection{Hole cross test}

Both doses, at $400 \mathrm{mg} / \mathrm{kg}$ and $200 \mathrm{mg} / \mathrm{kg}$ body weight produced a significant $(p<0.01)$ decrease of locomotion from its initial value during the period of the experiment (Figure 2). Maximum suppression of locomotor activity was displayed at the dose of $400 \mathrm{mg} / \mathrm{kg}$ body weight, which was comparable to the reference drug diazepam.

\subsection{Open field test}

The number of squares traveled by the mice was suppressed significantly in the second observation period at both dose levels (200 and $400 \mathrm{mg} / \mathrm{kg}$ body weight) of the methanol extract from the leaves of $L$. indica. The results were dose dependent and statistically significant (Figure 3).

\subsection{EPM test}

The methanol extract of $L$. indica at the dose of $400 \mathrm{mg} / \mathrm{kg}$ body weight, significantly increased the percentage of entries (Table 1) of mice into the open arms, and the percentage of time spent (Table 1) in the open arms of the EPM. The effects of treatment of mice at the dose of $200 \mathrm{mg} / \mathrm{kg}$ body weight, on open arm entries and time spent in open arms were dose dependent.

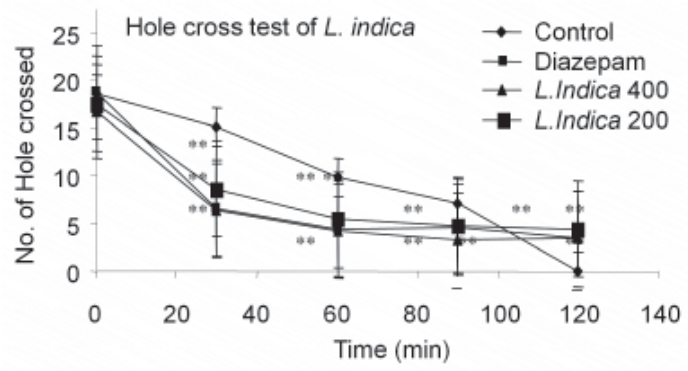

Figure 2. Effect of methanol extract from leaves of $\boldsymbol{L}$. indica on hole cross test in mice. Values are mean \pm S.E.M., $(n=5) ;{ }^{*} p<0.05,{ }^{* *} p<0.01$. Dunnet test as compared to control (Vehicle $=0.4 \mathrm{~mL} / \mathrm{mouse}$ ).

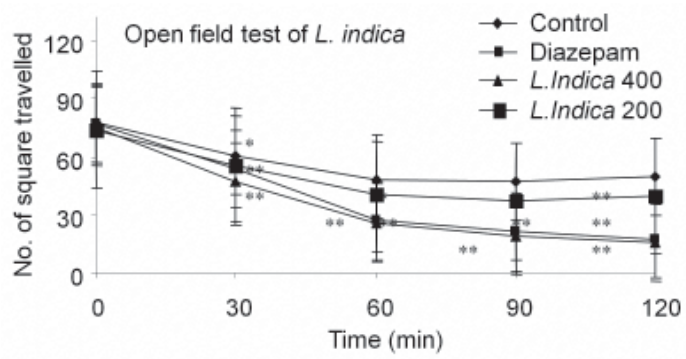

Figure 3. Effect of methanolic extract from leaves of $L$. indica on open field test in mice. Values are mean \pm S.E.M., $(n=5){ }^{*} p<0.05,{ }^{* *} p<0.01$, Dunnet test as compared to control (Vehicle $=0.4 \mathrm{~mL} /$ mouse) . 


\section{Discussion}

The present study demonstrated that the administration of different doses (200 and $400 \mathrm{mg} / \mathrm{kg}$ body weight) of methanol extract from $L$. indica leaves shows strong sedative and antianxiety properties. Both doses dependently potentiated sleep induced by thiopental suggesting that the leaves of the plant possesses a sleep inducing property. "Thiopental" basically a hypnotic agent, given at appropriate dose, induced hypnosis by potentiating GABA mediated postsynaptic inhibition through allosteric modification of $\mathrm{GABA}_{\mathrm{A}}$ receptors. Substances which possess CNS depressant activity either decrease the time for onset of sleep or prolong the duration of sleep or both $(14,15)$. In addition, the study on locomotor activity, as measured by hole cross and open field tests, showed that both doses of methanol extract from the leaves of $L$. indica decreased the frequency and the amplitude of movements. Since locomotor activity is a measure of the level of excitability of the CNS (16), this decrease in spontaneous motor activity could be attributed to the sedative effect of the plant extracts (17). Both doses significantly decreased locomotion in mice. The locomotor activity lowering effect was evident at the 2nd observation (30 min) and continued up to the 5th observation period (120 $\mathrm{min})$. The results were also dose dependent and statistically significant (Figures 2 and 3 ).

However, the anxiolytic effect was evidenced by the EPM test that has been recognized as a valuable model able to predict anxiolytic effects of drugs in rodents (18). The anxiolytic effect is observed when the experimental drug increases open arms entries without altering the total number of arm entries (19). Although the methanol extract at $200 \mathrm{mg} / \mathrm{kg}$ body weight, in mice, did not display a significant increase in the percentage of entries into open arms, the same extract at the dose of $400 \mathrm{mg} / \mathrm{kg}$ body weight showed a significant increase in the percentage of time spent in the open arms of the maze. This was slightly larger than the effects observed following treatment with the reference anxiolytic drug diazepam, in a dose dependent manner. These results could indicate an anxiolytic-like activity of the methanol extract from the leaves of $L$. indica.

$\mathrm{GABA}_{\mathrm{A}}$-benzodiazepine receptors are the most abundant inhibitory receptor (20) system in the CNS and binding of a benzodiazepine agonist to its recognition site results in increased chloride ion flux (21) which in turn hyperpolarizes the postsynaptic membrane at a level below that at which spike generation is possible and for this reason some $\mathrm{GABA}_{\mathrm{A}}$ agonists are frequently used for their hypnotic effects. The compounds identified from the leaves of $L$. indica $(22,23)$ contain ursolic acid and several other compounds like eicosanol, farnesol and $\beta$-sitosterol, act as $\mathrm{GABA}_{\mathrm{A}}$ agonists and this agonistic property could be attributed to the CNS depressant effect of $L$. indica leaves although there is no consensus about which substances are exactly responsible for these effects. However, further studies are necessary to evaluate the contribution of other substances that are isolated for the activity observed, because it still remains to be determined which components exactly were responsible for these effects.

\section{Conclusion}

The results from the experiments confirmed that the methanol extract from $L$. indica leaves possesses a strong sedative and anxiolytic potential. Therefore, we advance the suggestion that this extract may fulfill the therapeutic need for the treatment of anxiety and related neuropsychiatric disorders. However, further studies would be necessary to evaluate the contribution of other substances for the activity showed as it still remains to be determined which components were exactly responsible for these effects.

\section{Acknowledgement}

The authors thank Associate Prof. Dr. Shaikh Bokhtear Uddin (Department of Botany, University of Chittagong, Bangladesh) for identification of the plant material (www.mpbd.info).

\section{References}

1. Abid M, Hrishikeshavan HJ, Asad M. Pharmacological evaluation of Pachyrrhizus erosus (L.) seeds for centralnervous system depressant activity. Indian J Physiol Pharmacol. 2006; 50:143-151.

2. Wattanathorn J, Pangpookiew P, Sripanidkulchai K, Muchimapura S, Sripanidkuchai B. Evaluation of the anxiolytic and antidepressant effects of alcoholic extract of Kaempferia parviflora in aged rats. Am J Agri Biol Sci. 2007; 2:94-98.

3. Yusuf M, Wahab MA, Chowdhury JW, Japripa B. Medicinal Plants of Bangladesh. BCSIR Laboratory Press, Chittagong, Bangladesh, 1994; pp. 72-73.

4. Ghani A. Medicinal Plants of Bangladesh. The Asiatic Society of Bangladesh. Dhaka, Bangladesh. 2003; 181:502-504.

5. Rahman MA. Indigenous knowledge of herbal medicines in Bangladesh 3. Treatment of skin diseases by tribal communities of the hill tract districts. Bangladesh J Bot. 2010; 39:169-177.

6. Zhang ZJ. Therapeutic effects of herbal extracts and constituents in animal models of psychiatric disorders. Life Sci. 2004; 75:1659-1699.

7. Kirtikar KR, Basu BD. Data on medicinal plants and chemical constituents. In: Indian medicinal plants. VIMSAT Publishers, Bangalore, India, 1998; pp. 2532-2541.

8. Takagi K, Watanabe M, Saito H. Studies on the spontaneous movement of animals by the hole cross test; effect of 2-dimethyl-aminoethan and its acyl esters 
on the central nervous system. Jap J Pharmacol. 1971; 21:797-810.

9. Gupta BD, Dandiya PC, Gupta ML. A psychopharmacological analysis of behavior in rats. Jpn J Pharmacol. 1971; 21:293-298.

10. Royce JR. On the construct vality of open-field measures. Psychological Bull. 1977; 84:1098-1106.

11. Ferrini R, Miragoli G, Taccardi B. Neuro-pharmacological studies on SB 5833, a new psychotherapeutic agent of the benzodiazepine class. ArzneimittelForsch. 1974; 24:2029-2032.

12. Lister RG. The use of a plus-maze to measure anxiety in the mouse. Psychopharmacology (Berl). 1987; 92:180-185.

13. Pellow S, File SE. Anxiolytic and anxiogenic drug effects on exploratrory activity in an elevated plus-maze: A novel test if anxiety in rat. Pharmacol Biochem Behav. 1986; 24:525-529.

14. Nyeem MAB, Alam MA, Awal MA, Mostofa M, Uddin SJ, Islam N, Rouf R. CNS depressant effect of the crude ethanolic extract of the flowering tops of Rosa damascena. Iranian J Pharmacol Ther. 2006; 5:171-174.

15. Raquibul Hasan SM, Hossain MM, Akter R, Jamila M, Mazumder EHM, Rahman S. Sedative and anxiolytic effects of different fractions of the Commelina benghalensis Linn. Drug Discov Ther. 2009; 3:221-227.

16. Mansur RM, Martz W, Carlini EA. Effect of acute and chronic administration of Cannabis satis and (-) 9-trans tetrahydro cannabinaol on the behaviour of rats in open field arena. Psychopharmacology. 1980; 2:5-7.

17. Rakotonirina VS, Bum EN, Rakotonirena A, Bopelet M. Sedative properties of the decoction of the rhizom of Cyperus anticulatives. Fitoterapia. 2001; 72:22-29.

18. Perez RM, Perez JA, Garcia LM, Sossa H. Neuropharmacological activity of Solanum nigrum fruit. J Ethnopharmacol.1998; 62:43-48.

19. Barrett JE. Animal behavior models in the analysis and understanding of anxiolytic drugs acting at serotonin receptors. In: Animal Models in Psychopharmacology (Olivier B, Mos J, Slangen JL, eds.). Birkhäuser Verlag, Basel, Switzerland, 1991; pp. 37-52.

20. Squires RF, Braestrup C. Benzodiazepine receptors in rat brain. Nature. 1977; 266:732-734.

21. Trofimiuk, Walesiuk A, Braszko JJ. St John's wort (Hyperium perforatum) disminishes cognitive impairment caused by the chronic restraint stress in rats. Pharmacol Res. 2005; 51:239-246.

22. Srinivasan GV, Sharanappa P, Leela NK. Sadashiva CT, Vijayan KK. Chemical composition and anti microbial activity of the essential oil of Leea indica (Burm.f.) Merr. flowers. Natural product radiance. 2009; 8:488-493.

23. Srinivasan GV, Ranjith C, Vijayan KK. Identification of chemical compounds from the leaves of Leea indica. Acta Pharm. 2008; 58:207-214.

(Received April 10, 2011; Revised May 31, 2011; Rerevised June 06, 2011; Accepted July 04, 2011) 